\title{
ASPECTOS MORFO-HISTOQUÍMICOS DO VASO DEFERENTE DE Callichirus major (CRUSTACEA: AXIIDEA)
}

\author{
Tugstênio Lima de Souza ${ }^{1}$ \\ Adriane Araújo Braga ${ }^{2}$ \\ Erika Takagi Nunes ${ }^{3}$
}

Resumo: Callichirus major é um decápode encontrado na região entre-marés de ambientes costeiros, em especial praias com areia de baixa granulometria. Esta espécie tem sido amplamente explorada para ser usada como isca viva para pesca. Devido à inexistência de informação microscópica acerca de seu aparelho reprodutor, o presente estudo teve como objetivo caracterizar o vaso deferente como forma de contribuir para o entendimento de sua reprodução. Os animais, coletados ao longo da Praia do Corujão, em Piúma/ES, e, em laboratório, tiveram seus vasos deferentes dissecados para o processamento histológico de rotina. O vaso deferente foi caracterizado em três regiões: proximal (VDP), de epitélio cilíndrico com função secretora; média (VDM) e distal (VDD), com epitélio variando de pavimentoso a cúbico. No lúmen destas estruturas foi verificada a presença de matriz espermatofórica entre os espermatozoides, sendo esta intensamente reativa para os testes histoquímicos. Sendo assim, com base nas características observadas, foi possível compreender o papel funcional deste órgão na formação do conteúdo espermático desta espécie.

Palavras-chave: Corrupto; Reprodução; Espermatóforo; Decapoda.

\footnotetext{
${ }^{1}$ Ciências Biológicas/Universidade Federal do Espírito Santo, Brasil. E-mail: tugstenio94@hotmail.com.

2 Ciências Biológicas/Universidade Federal do Espírito Santo, Brasil. E-mail: dricrab@yahoo.com.br.

${ }^{3}$ Ciências Biológicas/Universidade Federal do Espírito Santo, Brasil. E-mail: erikatnunes@yahoo.com.br.
} 